\title{
Comparative Studies among Brassica Species to Identify Salinity Tolerant Genotypes of Rapeseed-Mustard
}

\author{
Vivek Sharma* and K.H. Singh \\ ICAR-Directorate of Rapeseed-Mustard Research, Bharatpur, India \\ *Corresponding author
}

\section{Keywords}

Brassica species, Cluster analysis, Salinity tolerance

Article Info

Accepted:

15 May 2019

Available Online:

10 June 2019

\section{A B S T R A C T}

Salinity tolerance genotypes is useful to cross with high yielding existing varieties to develop high yield hybrid that can grow in saline soil and saline water conditions. The different species of Brassica namely, B. juncea, B. carinata, B. napus B. campestris var toria were screened for salt tolerance and tolerant genotypes were identified. Comparisons of Brassica species use to identify salinity tolerance species and screening individual genotypes of rapeseed-mustard. A total number of 281 genotypes consisting $225 \mathrm{~B}$. juncea, 34 B. carinata, 18 B. napus, 4 B. campestris var toria were tested for salinity tolerance at levels of 100,150 and $200 \mathrm{mE}$ concentrations of saline water with distil water used as a control. Saline indices were recorded at seedling stage under lab conditions. Means, standard error and correlation were calculated by Microsoft Excel 2016 and SPSS 16.0, respectively. The two ways positioning hierarchal dendrogram, constellation plot and scatter plot matrix were also made by JMP SAS 25.0 software. The experiment was conducted in ICAR-Directorate of Rapeseed-Mustard Research, Bharatpur, India during 2016 - 2017. The initial results showed that correlations among germination (\%), root length $(\mathrm{cm})$ and shoot length $(\mathrm{cm})$ were significant at $\mathrm{P}<0.05$ and $\mathrm{P}<0.01$ level under control and saline conditions. Two ways hierarchical cluster analysis of genotypes were grouped into 7 clusters. In these clusters, cluster 5 include 4 genotypes and cluster 6 include 8 genotypes have salinity tolerance than other clusters. In which these genotypes have higher germination (\%) with high root and shoot length in lab conditions. In cluster 5 have F3 2(MJA 34/SSR 1-8)-7, F2 2(MJA 39/MJR 14)-6, F2 13-4, F2 12-2-1(4-9-2/EC 597309) genotypes and cluster 6 have F3 12-2-5(KLM 227/EC 597313), F2 13-3, F3 3(EC597309/NUDHYJ 3/RL 1359)-3 very early, F4 4(DMH 1)-3, 06-01-2006, F3 2(MJA 34/SSR 1-8)-6, HB 9910, 13-6-0, F3 7-4 genotypes salinity tolerance among whole collection. It will be necessary to screen these genotypes in field conditions for more precise results. Amphiploids species $B$. juncea and B. carinata significantly tolerance with high germination (\%), high relative shoot and root length than B. napus and diploid species, $B$. campestris var toria. It is inferred that amphiploids species are comparatively salt tolerant than their diploid relatives. Twelve genotypes namely from F3 2(MJA 34/SSR 1-8)-7, F2 2(MJA 39/MJR 14)-6, F2 13-4, F2 12-2-1(4-9-2/EC 597309), F3 12-2-5(KLM 227/EC 597313), F2 13-3, F3 3(EC597309/NUDHYJ 3/RL 1359)-3 very early, F4 4(DMH 1)-3, 06-01-2006, F3 2(MJA 34/SSR 1-8)-6, HB 9910, 13-6-0, F3 7-4 were identified as high salinity tolerance from this evaluation. 


\section{Introduction}

Salinity is one of the most prevalent abiotic stress next to drought that limiting the productivity of sustainable agriculture globally. Most of crops plant have brutal effect $\sim 20$ to $50 \%$ yield loss due to abiotic factor especially salinity Shrivastava and Kumar (2015). Saline soil characterized where electrical conductivity more than 4dS/m ～ $40 \mathrm{mM} \mathrm{NaCl}$; Chinnusamy, Jagendorf, and Zhu, 2005). About 6 to $10 \%$ of the world soils area is salt affected, which is around 12780millionhectares' area. It has been about $20 \%$ irrigated soil (1474 mha) salts effected (Chinnusamy et al., 2005; Munns and Tester, 2008). Nearly 6.73million-hectare area is affected by these stress in India and it will reach almost 20 million hectors by 2050Singh et al., (2014). According to the United Nations 2018, reports, $20 \%$ of agricultural land and $50 \%$ of world cultivated land are salt affectedCui et al., (2018).Furthermore, there is also a dangerous trend of a $10 \%$ per year increase in the saline area throughout the world. Normally salinity stress can adversely affect normal plant establishment Pessarakli et al., (2015), adverse effects on plant growth and development Izadi et al., (2014); Pakar et al., (2016); Panuccio et al., (2014); Pedler et al., (2004); Pessarakli et al., (2015), reduction in germination, plant heights and yield attributing characters as well as deterioration of the oil quality in brassica Rajendran et al., (2015). The Brassicase family consist of various types of field crops including several oil seed crops (like B. juncea, B. carinata, B. napus and B. campestris var B. campestris var toria). Mustard is the second most economically important oilseed crop contributing $7 \%$ of total edible oil in the world (Khan et al., 2002) and $30 \%$ in the India's oilseed economy Damodaram and Hegde (2010). Among the seven edible oilseeds cultivated in India, B. juncea is the dominant species along with B. rapa (syn. B. campestris L.) and B. napus L. grown. In India it is important source of edible oil, after groundnut in India. They are Indian mustard or raya [Brassica juncea (L.) Czern. and Coss.]; the ecotypes of $B$. campestris L. viz., toria, gobhisarson (B. napus L.) and Ethiopian mustard (B. carinata Braun.). Among B. species, Brassica juncea contributes $85 \%$ of the total rapeseed mustard production. Its maximum distribution area is centred in the North -West agro-climatic zone, where the majorities of ground water sources are highly saline. Therefore, increase demand of rapeseed-mustard oil production under salinity stress conditions are a growing concern.

Salinity stress is reducing nitrogen content in Brassica leaves, which leads to reduction in grain protein content ultimately, reduction in mobilization of micronutrients due to imbalance of ions is soil Ashraf (1994). However, reduction in growth and protein, it will also significant reduction in oil content. Therefore, it is urgently needed to develop salt tolerant genotypes will enable to achieve high productivity to fast growing population developing countries of the world. Selection and hybrid breeding including the use of wide crosses represent the best short term approach to development of salt tolerant plant. In the present study, we did find out salinity tolerance brassica species as well as individual genotypes among them.

\section{Materials and Methods}

\section{Plant materials and treatments}

The experiment was conducted in ICARDirectorate of Rapeseed-Mustard Research, Bharatpur, India during 2016 2017. It was preformed using of 281 genotypes (225 B. juncea, $34 \mathrm{~B}$. carinata, 18 B. napus, 4 B. campestris var toria) with 7 
checks (CS 54) of rapeseed-mustard. It was observed in a petri-dishes containing various saline solution and distilled water (DW) against salt resistance genotype, CS-54. The saline solutions were prepared by adding $\mathrm{NaCl}$ to distil water at three rates, 100, 150 and $200 \mathrm{mE} / \mathrm{L}$. There were needed of sterilized petri-dishes with sheet of a filter paper contained $5 \mathrm{ml}$ of each solution and on the alternative day water loss by replaced by weightage of distilled water or soil and water.

The experiment was conducted in dark condition for the first three days. Seed germination was observed using 25 seeds putin a petri-dish, $25 \pm 2^{\circ} \mathrm{C}$ temperature, 16 hrs. light period offer, $70 \%$ relative humidity (RH) for next four days and seed emergence counted after 7 days after sowing (DAS). It was recorded and expressed as per (ISTA (1996).

\section{Experimental design and analysis}

The seeds were germinated from third day (after dark period) to seven days. The seed was considered germinated when the length of radicle exceeds that of the seed.

It was counted on seventh days (final day count). Randomly five seedlings were selected after 7 DAS for recording shoot and root length of seedlings. The seedlings were measured of root length and shoot length.

Means of the observations recorded for the indices were compared after confirming data. The descriptive statistics of salt indices, i.e., means, standard error and correlation were done in Microsoft Excel 2016 and SPSS 16.0, respectively. The two ways positioning hierarchal dendrogram was clustering based on euclidean distance of the salt tolerance indices, were calculated by JMP SAS 25.0. The cluster groups were showed in constellation plot, association was depicted by scatter plot matrix, and the average of means of the multiple parameters in each cluster group was showed in cluster summary.

\section{Salinity indices}

Germination percentage and relative germination Li (2008)

Germination percentage $(\mathrm{G} \%)=\mathrm{n} / \mathrm{N} \times 100$,

Where $\mathrm{n}$ is the number of germinated seed at the seventh day; $\mathrm{N}$ is the number of total seeds.

Relative germination ratio $(\mathrm{RGR})=\mathrm{d} / \mathrm{e}$,

Where $\mathrm{d}$ is germination percentage in saline conditions, e is germination percentage in corresponding control.

Relative Salt injury $(\%)=1-\mathrm{d} / \mathrm{ex} 100$

Relative root/ shoot length ratio

Where, root/shoot length in saline conditions, against distilled water

\section{Comparison among of salinity tolerance different B. species genotypes rapeseed- mustard}

Based on germination percent, relative germination ratio and relative salt injury, seedlings were selected those who had highest germination \%, in different salinity levels, seedlings which had high germination $\%$ with high germination rate under higher level of salinity $(150 \mathrm{mE}$ and $200 \mathrm{mE})$ were selected as salinity tolerance genotypes. Means of genotypes in species were compared with other species. In which randomly selected five seedlings, which have high relative root length, high relative shoot length and relative salts injury seedlings emergences were measured. 


\section{Results and Discussion}

Correlation among relative germination ratio $(\%)$, relative shoot length, relative root length and root/shoot ratio

From Table 1b, Figure $1 \mathrm{a}$ and $1 \mathrm{~b}$, it was observed that when seeds were grown in a salt concentration $100 \mathrm{mE}$ and $150 \mathrm{mE}$, all the parameters i.e. germination (\%), shoot length, root length were highly correlated $(\mathrm{P}<0.01)$ among them at distil water, $100 \mathrm{mE}$ and 150 $\mathrm{mE}$, except germination $\%$ with root length at $100 \mathrm{mE}$; It means high tolerance genotypes had high germination percentage, high root length and high shoot length. When seedlings germinated on $100 \mathrm{mE}$ and $150 \mathrm{mE}$ were considered, the shoot length of seedlings germinated on distil water $(\mathrm{P}<0.05)$ was significantly different from that germinated on $100 \mathrm{mE}$ and $150 \mathrm{mE}(\mathrm{P}<0.01)$, suggesting that germination in salts condition had some selection effect for shoot length, while relative root length was not significantly different; the relative shoot lengths were significantly different among the tested genotypes $(\mathrm{P}<0.01)$.

Relationship was depicted by scatterplot among seedling traits at both salinity levels. The relationship was more scatter at $100 \mathrm{mE}$ and more linear at $150 \mathrm{mE}$ salinity levels. It was also show increase salinity levels, will increase correlation. Similarly, the scatter plot matrix is also a graphical tool used for illustrating the relationship between two variables (Fig. 1b).

The present investigation witnessed that abundant variability existing in given salinity tolerance of tested panel of Brassica genotypes. The significant positive relationship of seed yield with other traits suggesting indirect selection based on component traits would be helpful in improvement of the tolerance.
Effect of germination percentage by two salinity levels with control for comparing among different species of Brassica

As per data, graph line far form origin had tolerance that had high germination percentage at higher salinity levels. B. juncea had highest tolerance among $B$. species genotypes. B. carinata had also high tolerance from average of species. B. napus had lowest tolerance limit below than checks (Fig. 1b). It had also shown that when salinity levels just higher $(100 \mathrm{mE})$ from distil water $(0 \mathrm{mE})$, germination (\%) decline sharply. This pattern was showed all among brassica species genotypes. It has almost half germination at salinity level first $(100 \mathrm{mE})$ and almost no germination at second salinity level $(150 \mathrm{mE})$ except B. juncea. All of B. species do not germinated at highest salinity level200 mE). It had clearly distinguished germination $(\%)$ comparison of two effective salinities levels $100 \mathrm{mE}$ and $150 \mathrm{mE}$ (Figure 1b). It had almost negligible germination at salinity level $150 \mathrm{mE}$. B. campestris var $B$. campestris var toria had highest reduction in germination and it do not survive at higher salinity level $150 \mathrm{mE}$. From Table 1c, 1d, seeds were germinated under distilled water (control), $100 \mathrm{mE}, 150 \mathrm{mE}$ and $200 \mathrm{mE}$ salinity conditions.

If seeds were grown in salt conditions, highest germinations (\%) in B. juncea, in all salt concentration $(54.26 \%, 4.63 \% ; 100 \mathrm{mE}$ and $150 \mathrm{mE}$ ) than B. carinata, B. campestris var $B$. campestris var toria, B. napus. Relative germination ratio was also high in $B$. juncea than B. carinata, B. campestris var $B$. campestris var toria, B. napus. Genotypes of all four species expressed germination at $100 \mathrm{mE}$ and $150 \mathrm{mE}$ concentrations except $B$. campestris var B. campestris var toria, with significant reduction. Relative salt injury (\%) were high B. napus, $B$. campestris var $B$. campestris var toria and B. carinata. 
Fig.1a Tolerance graph lines had showed relation between germination percentage (0.00 to 100) on Y-axis and salinity levels (DW to $200 \mathrm{mE}$ ) on X-axis. Salinity tolerance species was far from origin.1b. Scatter plot showed correlation among relative germination ratio (\%), relative shoot length (RS), relative root length (RL) and root/shoot ratio (RR) at both salinity levels i.e. $100 \mathrm{mE}$ and $150 \mathrm{mE}$; Scatter plot with more compact and significant slope showed highly correlated. Plot with less compact and more scatter showed less correlation. A mean imaginary line of slop draws in each plot showed clearly relationship between traits. 2a and 2b. Comparison of different brassica sp. of average germination (\%) with standard error under two different salinity levels $(100 \mathrm{mE}$ and $150 \mathrm{mE})$. Germination percentage are given bottom of bar. 3a. Comparison of different brassica sp. of relative shoot length and relative root length under distil water (control) $\mathbf{3 b}$ and 3c. Comparison of different brassica sp. of relative shoot length and relative root length under two different salinity levels $(100 \mathrm{mE}$ and $150 \mathrm{mE})$

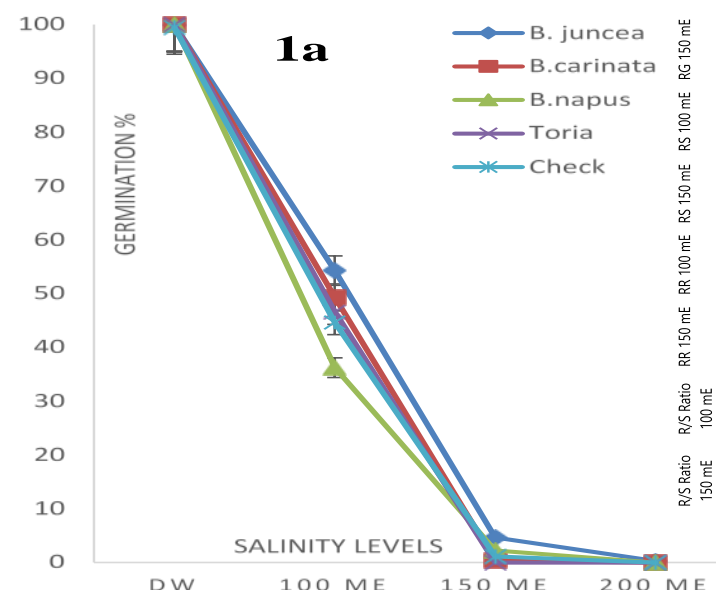

$100 \mathrm{ME}$

$\mathbf{2 a}$
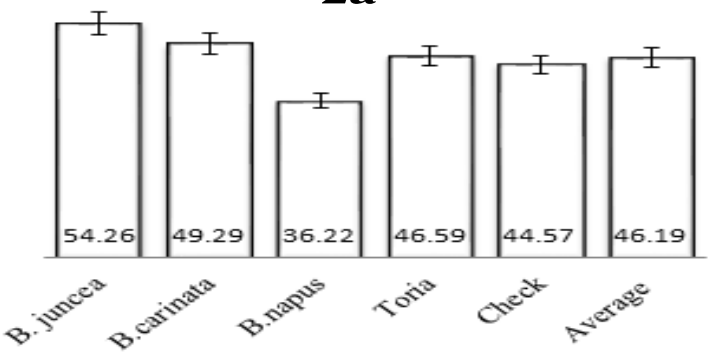

DW 3a

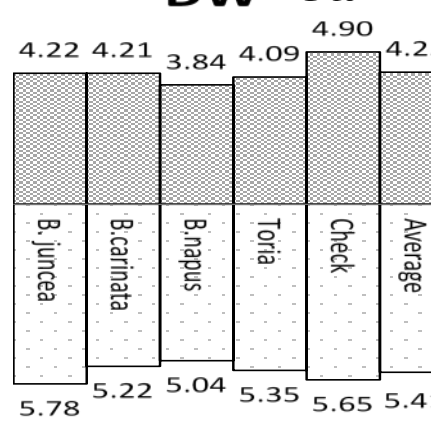

$\mathbf{1 b}$

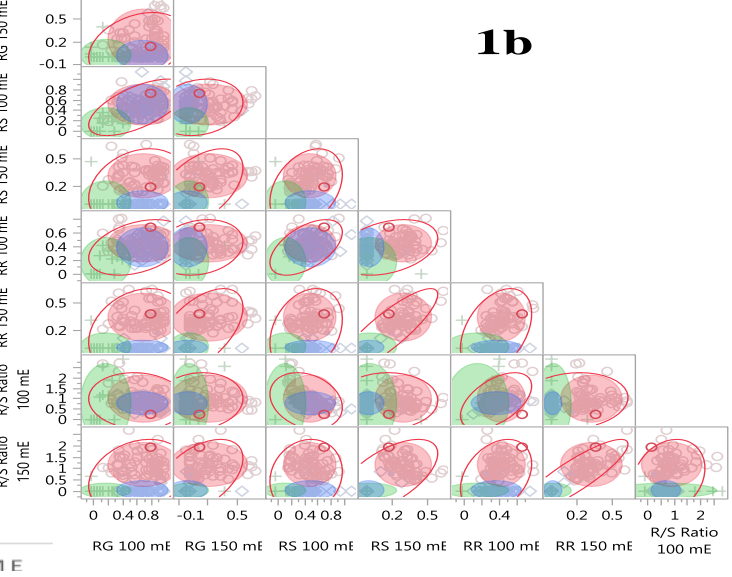

$150 \mathrm{mE}$

$2 \mathbf{b}$

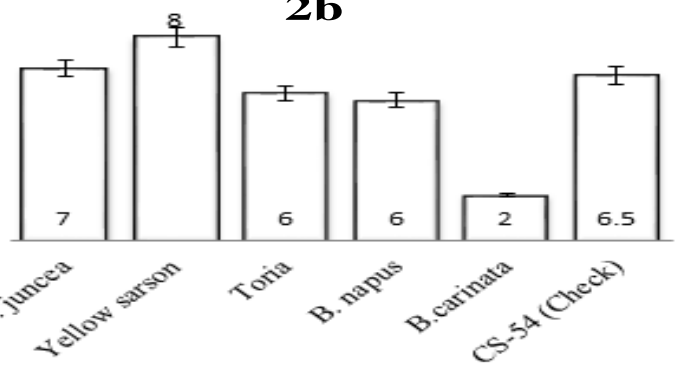

$150 \mathrm{mE}$

3c

3b

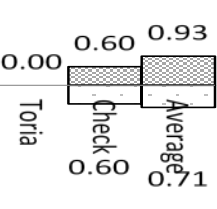


Fig 4a.Two ways hierarchical cluster analysis of 283 genotypes based on salt tolerance indices of seedlings germinated on two salinity levels (Euclidean distance) with control (distil water). 4b.Clustering of different brassica species and genotypes using constellation Plot 4c.Portion of total variation in each trait absorbed by clustering. 4d. highest trait contributing in cluster 7 (13.24) and cluster 6 (10.88) shows by cubic cluster creation (CCC). 4e. As saw above diagram, highest contributing trait in clustering i.e. germination \% at DW $(0.96)$ followed by relative root length at $150 \mathrm{mE}(0.86)$ and relative shoot length $(0.85)$
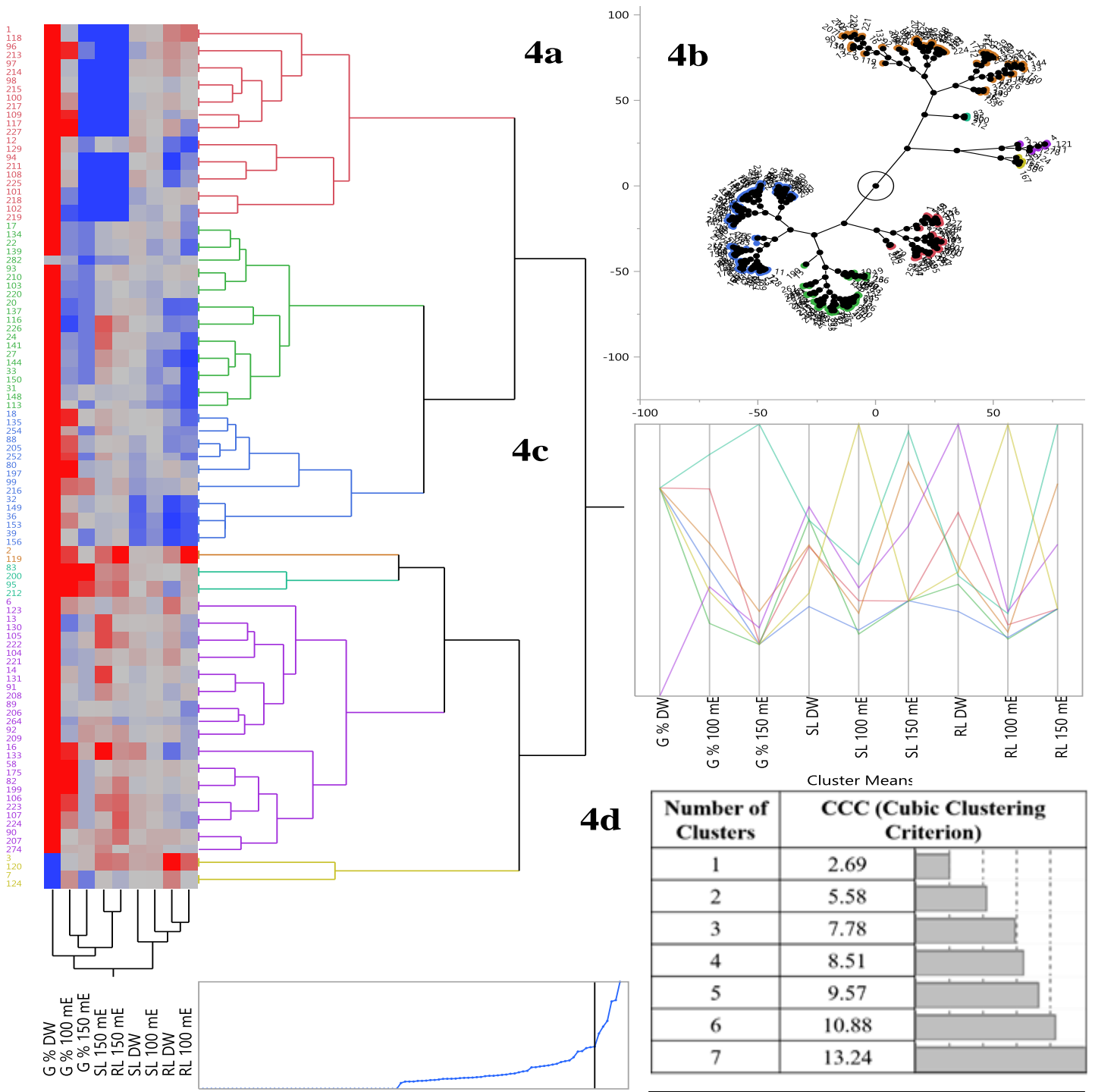

4d

\begin{tabular}{|c|c|c|}
\hline $\begin{array}{c}\text { Number of } \\
\text { Clusters }\end{array}$ & \multicolumn{2}{|c|}{$\begin{array}{c}\text { CCC (Cubic Clustering } \\
\text { Criterion) }\end{array}$} \\
\hline 1 & 2.69 & \\
\hline 2 & 5.58 & \\
\hline 3 & 7.78 & \\
\hline 4 & 8.51 & \\
\hline 5 & 9.57 & \\
\hline 6 & 10.88 & \\
\hline 7 & 13.24 & \\
\hline
\end{tabular}

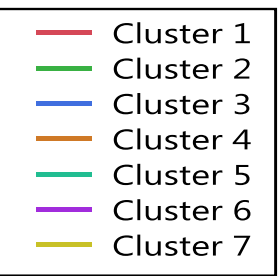

4e

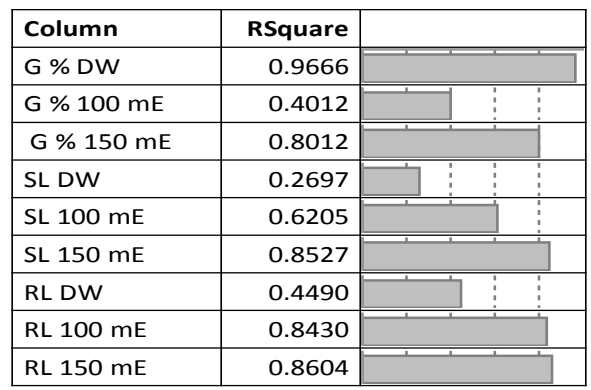


Table 1a Different salinity solutions were made up by using right amount of $\mathrm{NaCl}, \mathrm{CaCl}_{2}$ and $\mathrm{Na}_{2} \mathrm{SO}_{4}$ chemicals. It had showed different salinity levels with respect to EC, PH and temperature. 1b Correlations among relative germination (\%), relative shoot length, relative root length and root/shoot ratio at different levels of salinity. 1c.Effect of different salinity levels on germination traits in comparing among different species of Brassica genotypes. DW, Distil Water (control); mE, miliequivalent salinity treatment. 1d. Effect of different salinity levels on seedling traits (Relative shoot length, relative reduction shoot length (\%), relative root length and relative reduction root length $(\%)$ in comparing among different species of Brassica genotypes. 1e. Cluster-wise mean values of different characters in the studied brassica genotypes

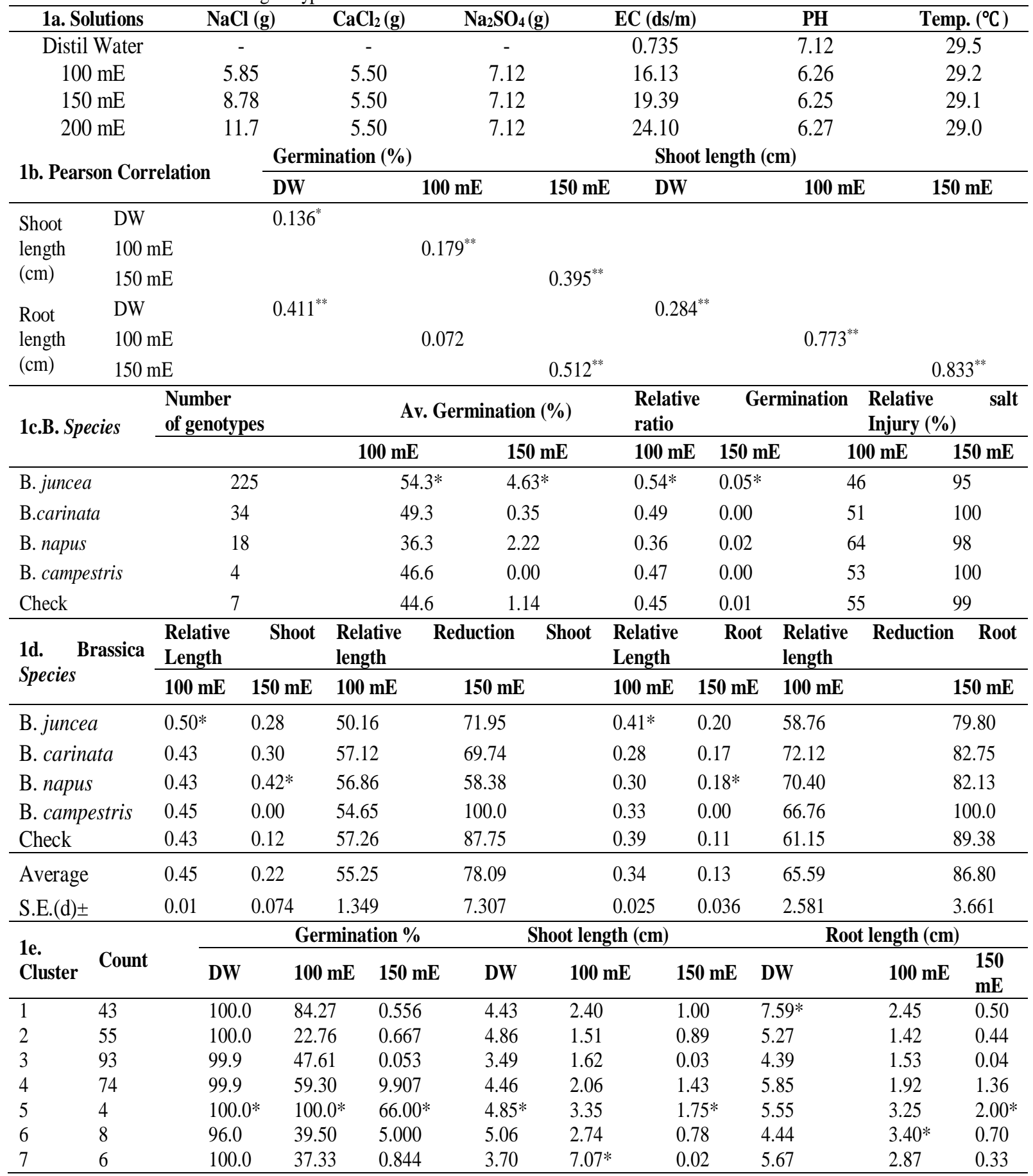

Note: * represents highest mean value of the character.

$*, * *$ Correlation is significant at the 0.05 level (2-tailed) and0.01 level (2-tailed) respectively in $1 \mathrm{~b}$ 
It was lowest in B. juncea. It was also observed that none of the genotypes of any species germinated at $200 \mathrm{mE}$ except $B$. juncea that was also negligible.

Based on germination percent at different salinity levels, $B$. juncea and $B$. carinata was found most salinity tolerant followed by $B$. campestris var B. campestris var toria.

Effect on seedling condition use to compare among different species of Brassica on the basis of Relative Shoot Length, Relative Reduction Shoot Length, Relative Root Length and Relative Reduction Root length

B. juncea, Relative root and shoot length were higher and Relative Reduction root and shoot length was lowest in under $100 \mathrm{mE}$ and 150 $\mathrm{mE}$ salt conditions. In $100 \mathrm{mE}$, Relative shoot length were higher in $B$. campestris var $B$. campestris var toria, B. juncea, yellow sarson and B. carinata. In $150 \mathrm{mE} \mathrm{B.} \mathrm{juncea,} \mathrm{B.}$ carinata and yellow sarson and B. campestris var toria.

Relative Root Length were highest in B. juncea, B. napus, B. carinata and lowest in yellow sarson. Relative Reduction Root length (\%) were lowest in B. juncea, B. napus and it were highest in yellow sarson and $B$. campestris var toria in all salt conditions (Table 1d).

The relative shoot was higher in B. campestris var toria as compare to other species under distil water and $100 \mathrm{mE}$ salt solutions (Table 1d). In higher salt solutions $150 \mathrm{mE}$, it was highest in $B$. juncea which was also highest relative root length under all conditions (Table 1d).It was relieved that $B$. juncea was perform best in all conditions and $B$. campestris var toria and individual check were performing better in distil water and lower salt solution $(100 \mathrm{mE})$ but not in higher salt solutions $150 \mathrm{mE}$ (Fig. 2a, 2b and 3).
Overall effect of average individual genotypes performances of different species of brassica

\section{Hierarchical clustering with their cluster summary}

Genotypes distributed into seven distinct clusters using cluster analysis which was performed on the 281 with two checks genotypes of B. species using three seedling traits at three salinity levels including control. The two way hierarchal dendrogram was framed using Ward's clustering method (Fig 4a). This method is based on minimizing the loss of information from joining two groups. Similarly, constellation plot was also developed which also distributed genotypes in 7 clusters (Fig. 4b). Clusters were homogenous within and heterogeneous between. Cluster summary (Table 1e) and illustrated diagram (Fig. 4c) were given. Thus, four genotypes of cluster $\mathrm{V}$ can be used as tolerance parent in the hybridization program with other genotypes to develop high yielding and salinity tolerance varieties. The magnitude of variation among the genotypes also directed the chance to use them through inter-genotypic improvement activities. Representative lines should be selected in cluster for hybrid programme. It can also have revealed ancient relationship with in cluster. Positive highest value of each added cluster was showed by cubic clustering criterion (CCC) to decide the number of clusters which covers maximum variations. It is shows maximum $\mathrm{R}$ square with maximum $\mathrm{CCC}$ value (13.24) in minimum number of cluster (Seven clusters; Fig. 4d). Clustering of salinity indices which maximum cover variation by germination $\%$ at $\mathrm{DW}(0.966)$ subsequently by root length at $150 \mathrm{mE}(0.86)$ and shoot length at $150 \mathrm{mE}(0.852$; Fig. 4e). The advanced breeding lines and released varieties refuge in same cluster registered that hitherto small portion of the available genetic 
diversity has been used in brassica improvement program in India. At the end it may be concluded that selection of genotypes from different groups and their proper accommodation in oil seed brassica hybridization programme would certainly increase the possibility of getting desired recombinants. Thus, hybridization of these genetically divergent parents could also lead to the development of better salinity promising brassica varieties.

\section{Overall salinity effects on seedlings growth traits of different species of brassica}

Salinity effects all the stages of plant but it is most sensitive stage at germination and early seedlings growth Ashraf (1994); Ashraf et al., (2001); Malik (1990). Our preliminary results showed based on average germination (\%), shoot length $(\mathrm{cm})$, root length $(\mathrm{cm})$ and root/shoot ratio. Seed germination begins with water intake. Salinity inhibits water imbibition in seed, thus it reduced early stage of seed germination Sharma et al., (2013) and accumulated of $\mathrm{Na}$ and $\mathrm{Cl}$ ions by osmotic ions potential during salt conditions. Prior studies have revealed reduces of germination leading to reduction in germination percentage. Brassica were inhibited by $\mathrm{NaCl}$ salt solutions, therefore use of $100 \mathrm{mE}, 150 \mathrm{mE}$ and $200 \mathrm{mE}$ of $\mathrm{NaCl}$ for seed inoculation and seedlings growth to compare to salts solutions. In early screening revealed, salts tolerance amphiploids species, $B$. juncea (AABB)superiors to diploids species $B$. campestris viz. toria and also superior to amphiploids $B$. carinata (BBCC) and $B$. napus (AACC)Ashraf et al., (2001); Kumar et al., (2015). There were also different conclusions made as significant inter and intra species variations for salts tolerance Ashraf et al., (2001); Huang and Redmann (1995); Su et al., (2013). Comparisons of different species of oilseed brassica it was found B.juncea, higher average germination percentage (\%) and have highest relative shoot and root length when it was grown in salt solutions $\mathrm{Su}$ et al., (2013). It has good performances in $100 \mathrm{mE}$ and $150 \mathrm{mE}$ salinity level. B. carinata was second highest average germination (\%) with had highest relative shoot and root length under control after check (CS-54) but negligible germination at $150 \mathrm{mE}$ salinity level. Checks (B. juncea) was performed lower than average of germinations. B. campestris var toria was third important species, was higher average germination (\%) with second highest relative shootand root length in all conditions except $150 \mathrm{mE}$ salt solution (no germination). B. napus was lowest germination at lower salinity level but higher germination in higher salinity conditions and also have highest relative shoot length at $150 \mathrm{mE}$ salinity level but have lowest germination and shoot length at $100 \mathrm{mE}$ and $B$. compestris var toria gave good performance in lower salt solution but poor performances in higher salt solution. The loss plant leads to reduce the yield by reduction plant density but It is not always true indices to salts tolerance and always correlated to with growth stage Maas et al., (1994); Viteri et al., (2012); Zeng et al., (2002). It was known that B. carinata have a high tolerance in nature and gave good results in field conditions but studied showed it was on second in average germination (\%) when it was grown in certain lab conditions. There was negligible germination at highest salinity level $200 \mathrm{mE}$.

Thus, out of four oilseed Brassica species, $B$. juncea (AABB) was found most salinity tolerant and B. napus was found least salinity tolerance. Results was based on different levels of salinity tolerance in B. juncea was observed till $200 \mathrm{mE}$ salt concentration but check was not grown in $200 \mathrm{mE}$ salt solution. Based on our results shoot were more porn to salt injury than root which is most convenient to use salinity indices. 
It was also observed that correlation among traits (germination (\%), root length and shoot length were high $(\mathrm{P}<0.01)$. it was suggested that higher germination (\%) was also high shoot and root length Sharma et al., (2013). Average root length and shoot length were shown above. It was showed, salinity had some selection effect on different genotypes. There were results in certain lab conditions, for authentic picture there was need to research in field conditions. Based on studied we suggested multiple parameters of relative germination rate, relative root length and relative shoot length might be more accurate in screening for salt tolerance in Brassica and related species.

\section{Acknowledgments}

The authors are thankful to the breeders of Directorate of Rapeseed-Mustard Research institutions who provided materials used and financial supports in this study.

\section{References}

Ashraf, M.: Organic substances responsible for salt tolerance inEruca sativa. Biologia Plantarum, 36, 255-259 (1994).

Ashraf, M., N. Nazir, et al.,: Comparative salt tolerance of amphidiploid and diploid Brassica species. Plant Science, 160, 683-689 (2001).

Chinnusamy, V., A. Jagendorf, et al.,: Understanding and Improving Salt Tolerance in Plants. Crop Science, 45, 437 (2005).

Cui, S., J. Zhang, et al.,: Leaching effectiveness of desalinization by rainfall combined with wheat straw mulching on heavy saline soil. Archives of Agronomy and Soil Science, 64, 891902 (2018).

Damodaram, T. and D.M. Hegde: Oilseeds situation, a statistical compendium,
2010.

Huang, J. and R.E. Redmann: Salt tolerance of Hordeum and Brassica species during germination and early seedling growth. Canadian Journal of Plant Science, 75, 815-819 (1995).

ISTA: International Rules for Seed Testing. Seed Science and Technology, 21 (1996)

Izadi, M.H., J. Rabbani, et al.,: Effects of salinity stress on physiological performance of various wheat and barley cultivars. Journal of Plant Nutrition, 37, 520-531 (2014).

Kumar, M., J.Y. Choi, et al.,: Molecular breeding in Brassica for salt tolerance: importance of microsatellite (SSR) markers for molecular breeding in Brassica. Frontiers in Plant Science, 6, 688 (2015)

Li, Y.: Effect of salt stress on seed germination and seedling growth of three salinity plants. Pakistan Journal of Biological Sciences, 11, 1268-1272 (2008).

Maas, E. V., S.M. Lesch, et al.,: Tiller Development in Salt-Stressed Wheat. Crop Science, 34, 1594 (1994).

Malik, R.S.: Prospects for brassica carinata as an oilseed crop in India. Experimental Agriculture, 26, 125-129 (1990).

Munns, R. and M. Tester: Mechanisms of Salinity Tolerance. Annual Review of Plant Biology, 59, 651-681 (2008).

Pakar, N., H. Pirasteh-Anosheh, et al.,: Barley growth, yield, antioxidant enzymes, and ion accumulation affected by PGRs under salinity stress conditions. Journal of Plant Nutrition, 39, 1372-1379 (2016).

Panuccio, M.R., S.E. Jacobsen, et al.,: Effect of saline water on seed germination and early seedling growth of the halophyte quinoa. AoB PLANTS, 6, plu047-plu047 (2014).

Pedler, J.F., T.B. Kinraide, et al.,: Zinc 
rhizotoxicity in wheat and radish is alleviated by micromolar levels of magnesium and potassium in solution culture. Plant and Soil, 259, 191-199 (2004).

Pessarakli, M., M. Haghighi, et al.,: Plant responses under environmental stress conditions. Adv. Plants Agric. Res. J, 2, 73 (2015).

Rajendran, S.R.C.K., Y.Y. Yau, et al.,: CRISPR-Cas9 Based Genome Engineering: Opportunities in AgriFood-Nutrition and Healthcare. OMICS: A Journal of Integrative Biology, 19, 261-275 (2015).

Sharma, P., V. Sardana, et al.,: Salt tolerance of Indian mustard (Brassica juncea) at germination and early seedling growth. Environmental and Experimental Biology, 39-46 (2013).

Shrivastava, P. and R. Kumar: Soil salinity: A serious environmental issue and plant growth promoting bacteria as one of the tools for its alleviation. Saudi Journal of
Biological Sciences, 22, 123-131 (2015).

Singh, J., P.C. Sharma, et al.,: Assessing the effect of salinity on the oil quality parameters of Indian mustard (Brassica juncea L. Czern and Coss) using Fourier Transform Near-Infrared Reflectance (FT-NIR) spectroscopy. Grasas y Aceites, 65, 009 (2014).

$\mathrm{Su}$, J., S. Wu, et al.,: Comparison of Salt Tolerance in Brassicas and Some Related Species. American Journal of Plant Sciences, 04, 1911-1917 (2013).

Viteri, F.E., E. Casanueva, et al.,: Antenatal iron supplements consumed daily produce oxidative stress in contrast to weekly supplementation in Mexican non-anemic women. Reproductive toxicology (Elmsford, N.Y.), 34, 125-32 (2012).

Zeng, L., M.C. Shannon, et al.,: Evaluation of salt tolerance in rice genotypes by multiple agronomic parameters. Euphytica, 127, 235-245 (2002).

\section{How to cite this article:}

Vivek Sharma and Singh, K.H. 2019. Comparative Studies among Brassica Species to Identify Salinity Tolerant Genotypes of Rapeseed-Mustard. Int.J.Curr.Microbiol.App.Sci. 8(06): 20732083. doi: https://doi.org/10.20546/ijcmas.2019.806.247 